\title{
Synthesis and characterization of silicon-doped polycrystalline GaN films by r.f. sputtering
}

\author{
S GUPTA ${ }^{1,2}$ \\ ${ }^{1}$ Department of Materials Science, Indian Association for the Cultivation of Science, Calcutta 700 032, India \\ ${ }^{2}$ Department of Engineering Physics, The Oxford College of Engineering, Bangalore 560 068, India
}

MS received 22 January 2015; accepted 11 May 2015

\begin{abstract}
Silicon-doped polycrystalline GaN films were successfully deposited at temperatures ranging from 300 to $623 \mathrm{~K}$ on fused silica and silicon substrates by radio frequency (r.f.) magnetron sputtering at a system pressure of $\sim 5 \mathrm{~Pa}$. The films were characterized by optical as well as microstructural measurements. The optical properties were studied by UV-vis-NIR spectrometer and photoluminicence (PL) measurements. The microstructural information was obtained from scanning electron microscope (SEM), energy-dispersive $\mathrm{X}$-ray spectroscopy (EDX), atomic force microscopy (AFM) and X-ray diffraction (XRD) studies. PL measurement at $80 \mathrm{~K}$ exhibited two strong transitions located at $\sim 2.1$ and $\sim 2.7 \mathrm{eV}$ along with lower intensity peaks for luminescence at the higher energy side at $\sim 3.45$ and $\sim 3.3 \mathrm{eV}$ for all the films deposited here, and the peaks at $\sim 3.45$ and $\sim 3.3 \mathrm{eV}$ could be ascribed to transitions related to excitons bound to a neutral donor for $\mathrm{h}-\mathrm{GaN}$ and $\mathrm{c}-\mathrm{GaN}$, respectively. A broad peak at $\sim 2.1 \mathrm{eV}$ indicated the presence of yellow luminescence in all the films. The SEM and AFM images revealed that the films are compact with well-dispersed polycrystalline constituting the films. The XRD traces contained the signature of both the hexagonal and cubic phases of GaN.
\end{abstract}

Keywords. Group III nitrides; r.f. sputtering; optical and microstructural properties.

\section{Introduction}

It is an increasingly accepted fact that the group III nitrides originate from their promising potential for shortwavelength light-emitting diodes, semiconducting lasers and optical detectors, and for high temperature, high power and high frequency devices as well. The main technological interest in the polycrystalline-based devices stems from its very low-cost production. Among different group III nitrides, GaN being a direct bandgap semiconductor has shown great promise towards the above applications.

The control of doping in wide bandgap semiconductors like $\mathrm{GaN}$ is difficult due to the formation of native defects. Probability of defect formation increases with the increase in bandgap, while the enthalpy for defect formation is lower than the bandgap energy. Jenkins and Dow ${ }^{1}$ concluded from their analysis that the native defects are responsible for the usual n-type character and that a shallow hydrogenic donor in this material can be related to nitrogen vacancy. According to Neugebaur and Van der Walle, ${ }^{2}$ nitrogen vacancies seems to be energetically most favourable, followed by antisites and interstitials. At this juncture, what remains to be seen that how Silicon being most common n-type dopant in $\mathrm{GaN}$ can rectify the

(guptasnigdha646@gmail.com) different properties in polycrystalline $\mathrm{GaN}$ thin films by radio frequency (r.f.) sputtering.

Depending on the growth conditions, GaN crystallizes either in the stable hexagonal (wurtzite phase) or metastable cubic (zinc blend phase) polytypes. The prevalent deposition techniques for depositing $\mathrm{GaN}$ thin films are mainly metal organic chemical vapour deposition (MOCVD) and molecular beam epitaxy (MBE).

It is well documented in the literature that the growth of $\mathrm{GaN}$ in polycrystalline form is based on $\mathrm{MBE},{ }^{3-5}$ $\mathrm{MOCVD}^{6-8}$ and post-nitridation technique. ${ }^{9,10}$ In recent times, amorphous and polycrystalline $\mathrm{GaN}$ thin films have been deposited by using both magnetron sputtering technique $^{11-14}$ and laser ablation ${ }^{15-18}$ technique. In this communication, the synthesis of polycrystalline silicon (1 at \%)-doped $\mathrm{GaN}$ films by the r.f. sputtering technique at reasonably lower temperature is reported. The films were characterized by measuring optical and microstructural properties to derive meaningful information in the films.

\section{Experimental}

Silicon-doped polycrystalline GaN thin films were deposited onto fused silica substrates by r.f. sputtering of a GaN target (99.999\%) containing 1 at\% $\mathrm{Si}$ in argon plasma and a combination of $\mathrm{Ar}$ and $\mathrm{N}_{2}$ plasma at a system 
pressure of $\sim 5 \mathrm{~Pa}$. The films were deposited at different substrate temperatures ranging from 300 to $623 \mathrm{~K}$ and for a fixed deposition time of $\sim 3 \mathrm{~h}$. The substrates were placed on a heavy circular copper block that were heated by appropriate heating coils passing through holes laterally drilled through the copper block. The temperature of the substrates were monitored and controlled by a copperconstantan thermocouple through an on/off electronic temperature controller. Before starting the actual deposition, the target was pre-sputtered with a shutter located in between target and substrate. All the depositions were performed with a $140 \mathrm{~W}$ r.f. power from a power supply capable of delivering $1.0 \mathrm{~kW}, 13.56 \mathrm{mHz}$. The diameter of the target was $2.5 \mathrm{~cm}$. The distance between the target and substrate was $\sim 3.5 \mathrm{~cm}$. Optical studies were performed by measuring transmittance in the wavelength region of $\lambda=200-800 \mathrm{~nm}$ using a spectrophotometer (Hitachi-U3410) at room temperature. The spectra were recorded with a resolution of $\lambda \sim 0.07 \mathrm{~nm}$ along with a photometric accuracy of $\pm 0.3 \%$ for transmittance measurements. Scanning electron microscope (SEM) images were obtained from a Hitachi SEM and atomic force microscopy (AFM) images were obtained with Nanoscope-IV (Digital Instruments). Photoluminescence (PL) spectra were recorded using a Perkin Elmer LS55 spectrometer along with a $300 \mathrm{~W}$ xenon arc lamp as the emission source. A Hamamatsu photomultiplier was used as the detector along with a $1 / 4 \mathrm{~m}$ monochromator. Fourier transform infrared (FTIR) spectra were recorded by a Nicolet (MAGNA-IR-750) spectrometer.

\section{Results and discussion}

\subsection{Microstructural study}

The GaN films were deposited by r.f. sputtering onto fused silica substrates kept at different substrate temperatures $\left(T_{\mathrm{s}}\right)$, as indicated in table 1 . It was observed that films with different grain sizes $(D)$ were obtained by varying the substrate temperatures during sputtering of the $\mathrm{GaN}$ target. The SEM images of two representative nanocrystalline $\mathrm{GaN}$ films deposited at substrate temperatures at $\sim 423$ and $623 \mathrm{~K}$ along with the corresponding grain size distribution are shown in figure 1. The SEM images (figure $1 \mathrm{a}$ and $\mathrm{b}$ ) revealed that the films were compact with well dispersed polycrystalline constituting the films. The grain sizes obtained from the SEM pictures varied from 0.18 and $0.35 \mu \mathrm{m}$ with the increasing substrate temperature during deposition. Gradual increase in grain size was observed for films as the substrate temperature was increased from 300 to $623 \mathrm{~K}$. The grain sizes $(D)$ of the GaN films obtained from optical measurements (discussed later) were found to vary from 0.12 to $0.25 \mu \mathrm{m}$ (table 1 ), which tallied well with that obtained from SEM studies. AFM pictures of four representative polycrystalline Si-doped GaN films deposited at 300, 423, 523 and $623 \mathrm{~K}$ are shown in figure $2 \mathrm{a}-\mathrm{d}$, respectively. One can observe that the grain size increased with the increase in substrate temperature during deposition.

Figure 3 shows the XRD trace of a representative film deposited at $423 \mathrm{~K}$. It may be observed that the XRD data have contained the signature of both the hexagonal and cubic phases of GaN. The spectrum is dominated by sharp and intense peaks corresponding to reflections from (002) plane for $\mathrm{c}-\mathrm{GaN}^{3}$ and another $\mathrm{c}-\mathrm{GaN}$ peak from (111) plane followed by peaks for $\mathrm{h}-\mathrm{GaN}$ for reflections from (101), (103), (201), (004) and (202) planes (JCPDS data file). The relative intensity of the peaks for c-GaN and h-GaN decreases for films deposited at lower substrate temperature during deposition. It may also be noted that the peaks became sharper for films deposited at higher substrate temperatures indicating grain growth in these films. The average grain size $L$ can be calculated by Scherer's formula as

$$
L=\frac{0.91 \lambda}{D \cos \theta}
$$

where $\lambda$ is the wavelength of $\mathrm{X}$-ray and $D$ the full-width at half-maximum (FWHM) of the (0002) reflection peak while $\theta$ the Bragg angle. The grain sizes were found to be $0.18,0.22,0.24$ and $0.32 \mu \mathrm{m}$, respectively, which are in agreement with those obtained from optical studies. Furthermore, it was noticed that there was a decrease in the FWHM of (002) peaks with the increase in the film thickness. The latter indicated that the grain size of the poly-GaN, which could be calculated from FWHM of (002) peaks, became larger in thicker films. The result is consistent with that from SEM and AFM. It might be noted here that the films deposited at temperatures between 300 and $423 \mathrm{~K}$ showed predominant hexagonal

Table 1. Different parameters obtained from Si-doped polycrystalline $\mathrm{GaN}$ deposited at different substrate temperatures.

\begin{tabular}{lcccccc}
\hline $\begin{array}{l}\text { Film } \\
\text { name }\end{array}$ & $\begin{array}{c}\text { Substrate } \\
\text { temp. }(\mathrm{K})\end{array}$ & $\begin{array}{c}\text { Thickness } \\
(\mu \mathrm{m})\end{array}$ & $\begin{array}{c}\text { Roughness } \\
(\mathrm{nm})\end{array}$ & $\begin{array}{c}\text { Grain size } \\
(\mu \mathrm{m})\end{array}$ & Bandgap $(\mathrm{eV})$ & $\mathrm{N}\left(\mathrm{cm}^{-3}\right)$ \\
\hline S-1 & 300 & 0.20 & 11 & 0.12 & 3.42 & $9.54 \times 10^{18}$ \\
S-2 & 423 & 0.22 & 15 & 0.16 & 3.35 & $9.65 \times 10^{18}$ \\
S-3 & 523 & 0.27 & 19 & 0.21 & 3.27 & $9.85 \times 10^{18}$ \\
S-4 & 623 & 0.30 & 24 & 0.25 & 3.18 & $2.54 \times 10^{19}$ \\
\hline
\end{tabular}



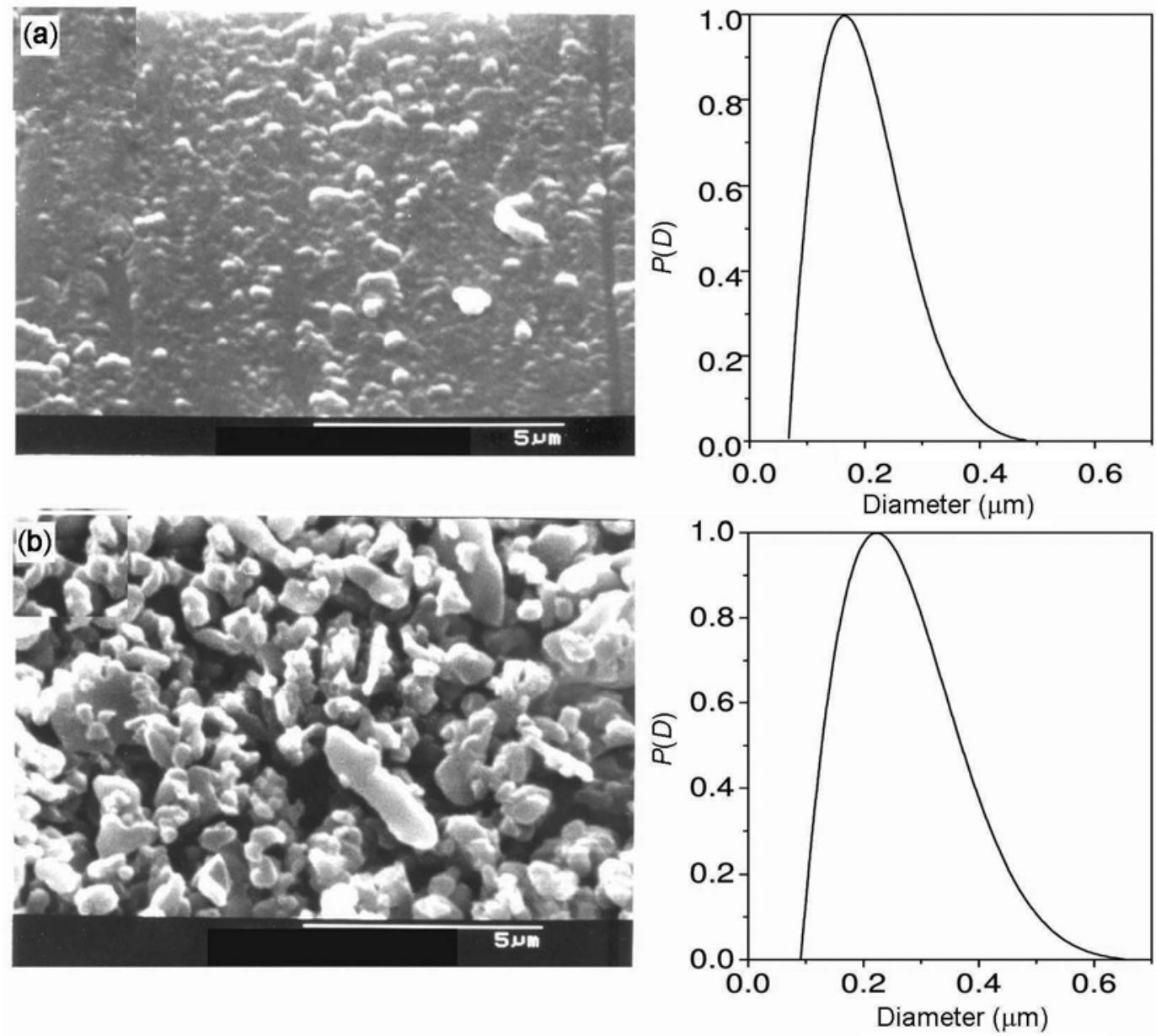

Figure 1. SEM micrographs of two representative Si-doped GaN films deposited at (a) 523 and (b) $623 \mathrm{~K}$.

phase with reflections from (101) and (103) planes for $\mathrm{h}-\mathrm{GaN}$, while those deposited above $523 \mathrm{~K}$ indicated predominant cubic phase of $\mathrm{GaN}$ showing reflections from (002) and (111) planes of c-GaN. Films deposited at intermediate temperatures were seen to contain mixed phases with a relative content of cubic phase that increased with the increase in $T_{\mathrm{s}}$. Peaks located at $2 \theta=$ $47.5^{\circ}$ and $56.2^{\circ}$ might be identified with the reflections from (220) and (311) planes of Si. The presence of Si peaks in the XRD pattern may be described as the presence of $\mathrm{Si}$ atoms at the surface of the films or it might come from fused silica substrate. The energy-dispersive X-ray spectroscopy (EDX) spectra confirm the presence of $\mathrm{Si}$ peaks along with the $\mathrm{Ga}$ and $\mathrm{N}_{2}$ peaks. The elemental detection from EDX measurements reveals $53 \% \mathrm{~N}_{2}, 45 \% \mathrm{Ga}$ and 2 at $\%$ of $\mathrm{Si}$ in the presence of $\mathrm{Ar}+\mathrm{N}_{2}$ plasma during the deposition of films and that of $38.5 \% \mathrm{~N}_{2}, 60 \% \mathrm{Ga}$ and 1.5 at $\%$ of $\mathrm{Si}$ in the presence of Ar plasma.

\subsection{Bandgap and optical constants}

The absorption coefficients $(\alpha)$ of the Si-doped GaN films were determined by measuring transmittance and reflectance in these films. ${ }^{19,20}$ In general, the absorption coefficient $(\alpha)$ may be written as a function of the incident photon energy $(h v)$ so that

$$
\alpha h v=B\left(h v-E_{\mathrm{g}}\right)^{m},
$$

where $m$ indicates the nature of a particular transition and may be obtained from the plot of $\ln (\alpha h v) v s . \ln \left(h v-E_{\mathrm{g}}\right)$, as shown in the inset of figure 4 . We estimated $m=0.48$ for this representative $\mathrm{GaN}$ film, which indicated an allowed direct optical transition. The bandgap $\left(E_{\mathrm{g}}\right)$ was determined from the plot of $(\alpha h v)^{2} v s . h v$, as shown in figure 4, for a representative film deposited at $T_{\mathrm{s}}=300 \mathrm{~K}$ showing $E_{\mathrm{g}} \sim 3.42 \mathrm{eV}$. The bandgaps obtained for films deposited at different substrate temperatures $\left(T_{\mathrm{s}}\right)$ are shown in figure 5 and table 1 . It could be observed that the films deposited at temperatures $\sim 300 \mathrm{~K}$ had bandgap $\sim 3.4 \mathrm{eV}$, which is equal to the bandgap of h-GaN. Films deposited at subsequently higher temperatures indicated gradual lowering of bandgap attaining $\sim 3.2 \mathrm{eV}$ for c-GaN for films deposited at $T_{\mathrm{s}}>523 \mathrm{~K}$. This clearly corroborates the observation from the XRD studies that the films deposited at higher temperature $(T>523 \mathrm{~K})$ 

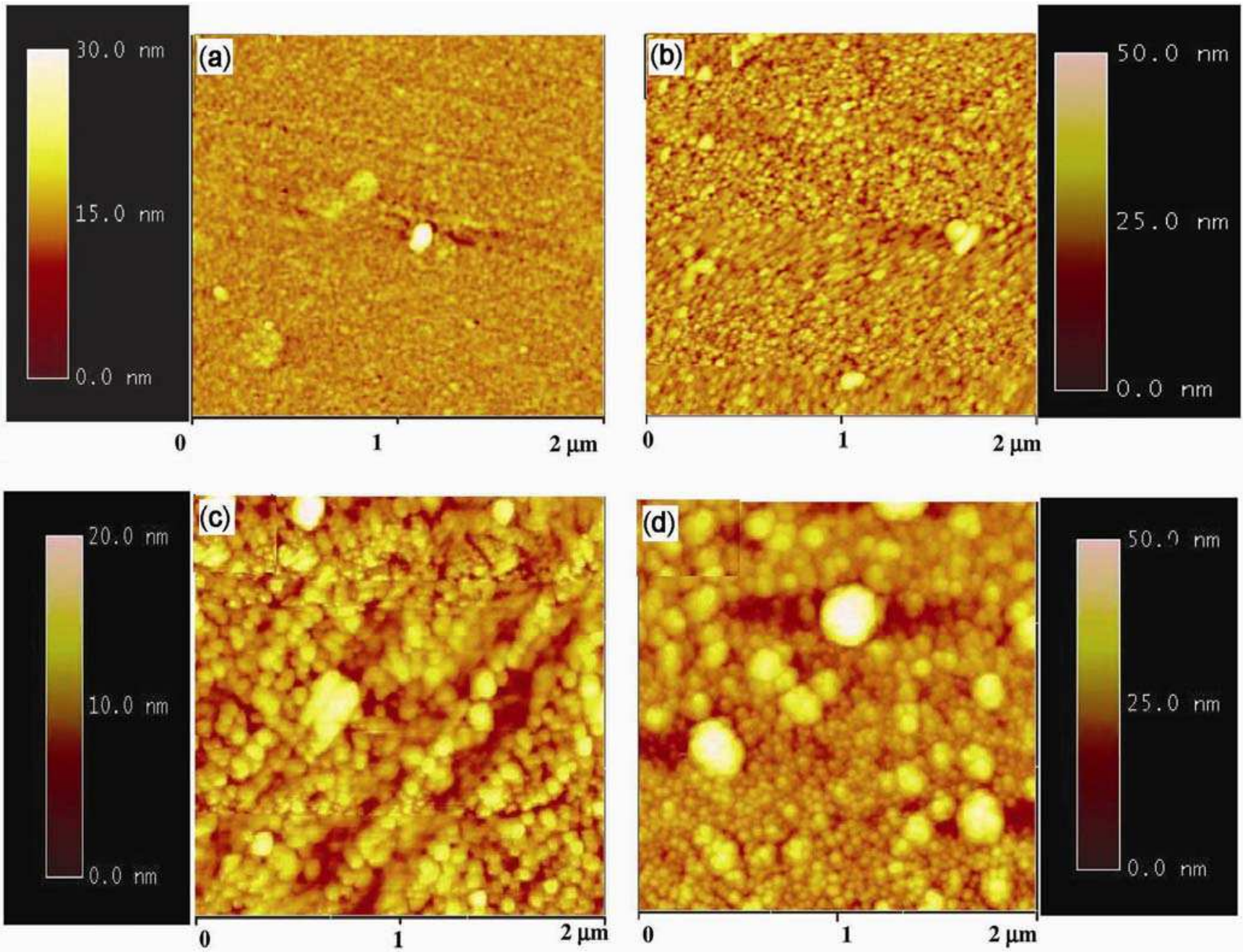

Figure 2. AFM pictures of some representative Si-doped GaN films deposited at (a) 300, (b) 373, (c) 523 and (d) $623 \mathrm{~K}$.

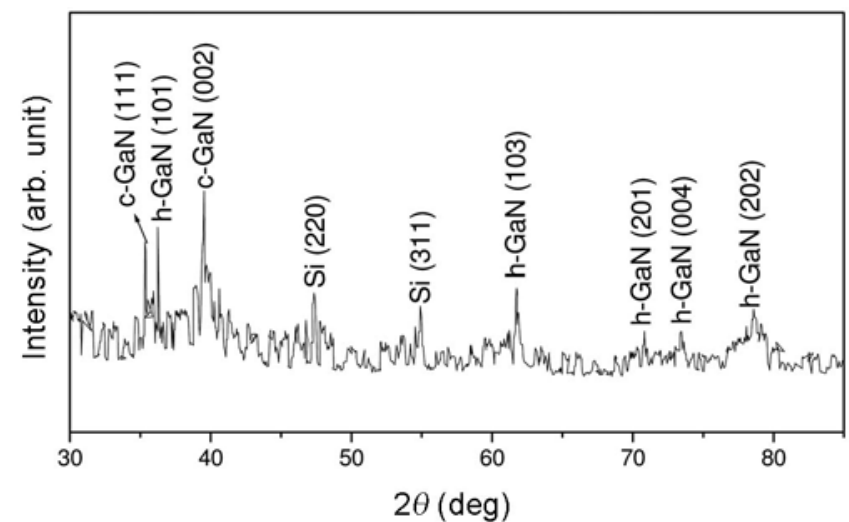

Figure 3. XRD spectrum of a representative film deposited at $623 \mathrm{~K}$.

contained higher c-GaN phase. The optical constants (refractive index $n$ and extinction coefficient $k$ ) of the polycrystalline GaN films were determined from the

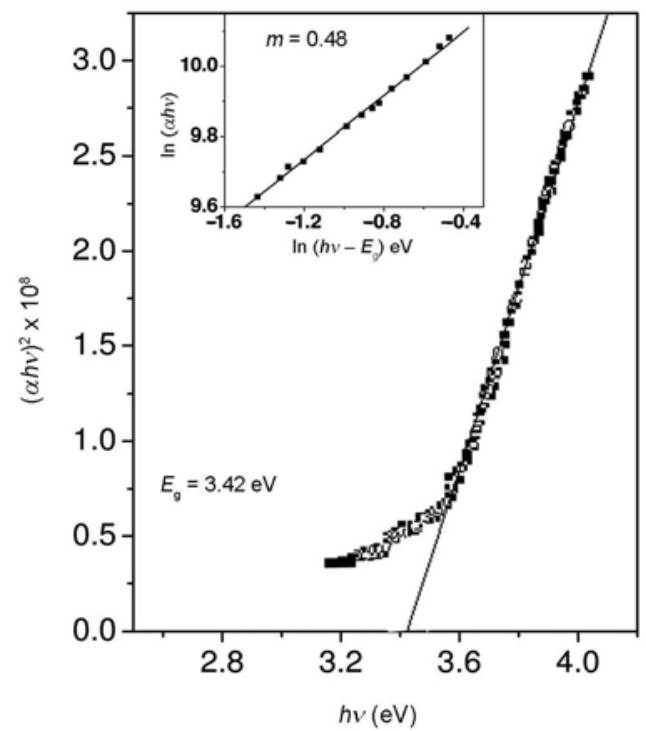

Figure 4. Plot of $(\alpha h v)^{2} v s$. $h v$ of a representative film deposited at $T_{\mathrm{s}}=300 \mathrm{~K}$. Inset shows the plot of $\ln (\alpha h v) v s \cdot \ln \left(h v-E_{\mathrm{g}}\right)$. 


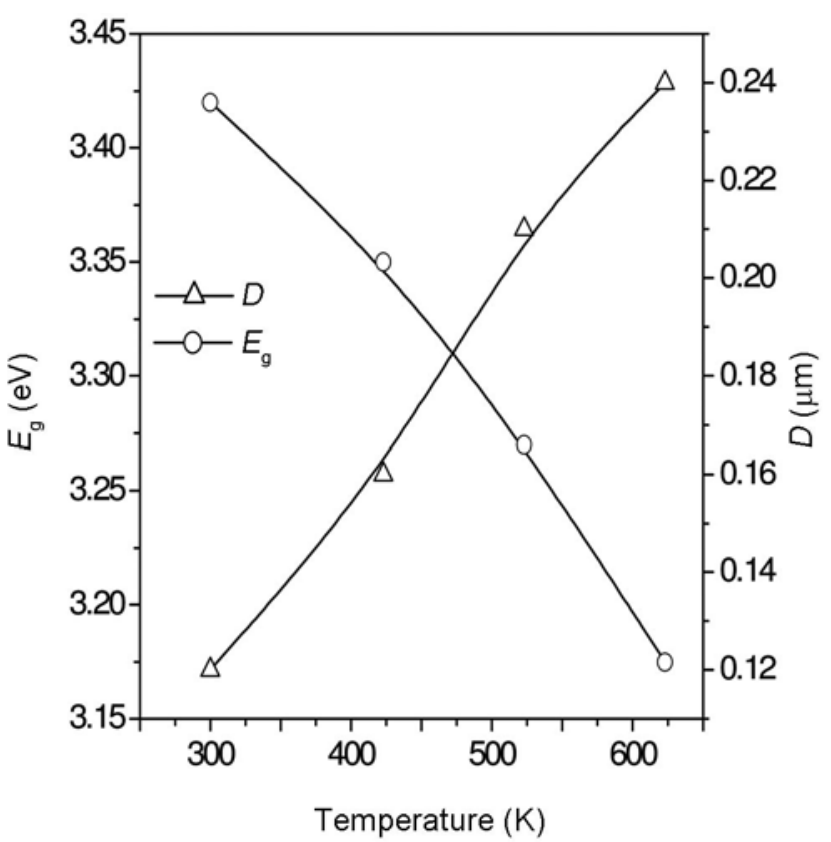

Figure 5. Variation of bandgap $\left(E_{\mathrm{g}}\right)$ and grain diameter $(D)$ with substrate temperature $\left(T_{\mathrm{s}}\right)$ during deposition.

transmittance and/or reflectance $v s$. wavelength traces by using the standard relations. ${ }^{19,20}$ Variation of refractive index and extinction coefficient with $h v$ have been shown in figure $6 \mathrm{a}$ and $\mathrm{b}$, respectively. It may be observed that the refractive index increased for films deposited at increased substrate temperature during deposition. The refractive index tends to attain the bulk value $(\sim 2.1)$ for c-GaN for films deposited at higher substrate temperature while the absorption coefficient increased significantly for films with higher c-GaN content.

\subsection{Grain distribution and surface roughness}

Surface roughness $\left(\sigma_{0}\right)$ which is the rms height fluctuations of the surface irregularities can be obtained by recording the diffused part of the reflectance $\left(R_{\text {diff }}\right)$ from the film surface. ${ }^{21} \mathrm{We}$ recorded both the specular $(R)$ and diffused $\left(R_{\text {diff }}\right)$ part of the reflectance and $\sigma_{0}$ was determined from the variation of $R /\left(R+R_{\text {diff }}\right)$ with wavelength ( $\lambda$ ) by using the relation ${ }^{21}$

$$
\ln \left[R / R_{0}\right]=-\left(4 \pi \sigma_{0}\right)^{2} / \lambda^{2}+\text { constant, }
$$

where $R_{0}=R+R_{\text {diff. }}$. The surface roughness $\left(\sigma_{0}\right)$ for the $\mathrm{GaN}$ films deposited at different temperatures was obtained from the slopes of the plots (not shown here) of $\ln \left(R_{0} / R\right) v s .1 / \lambda^{2}$. The surface roughness $\left(\sigma_{0}\right)$ varied between 11 and $24 \mathrm{~nm}$ (table 1 ) and the roughness increased for films deposited at higher temperature.

Distribution of grain sizes in these polycrystalline films could also be conveniently evaluated by measuring diffuse $\left(R_{\text {diff }}\right)$ and specular $\left(R_{0}\right)$ reflections from the film
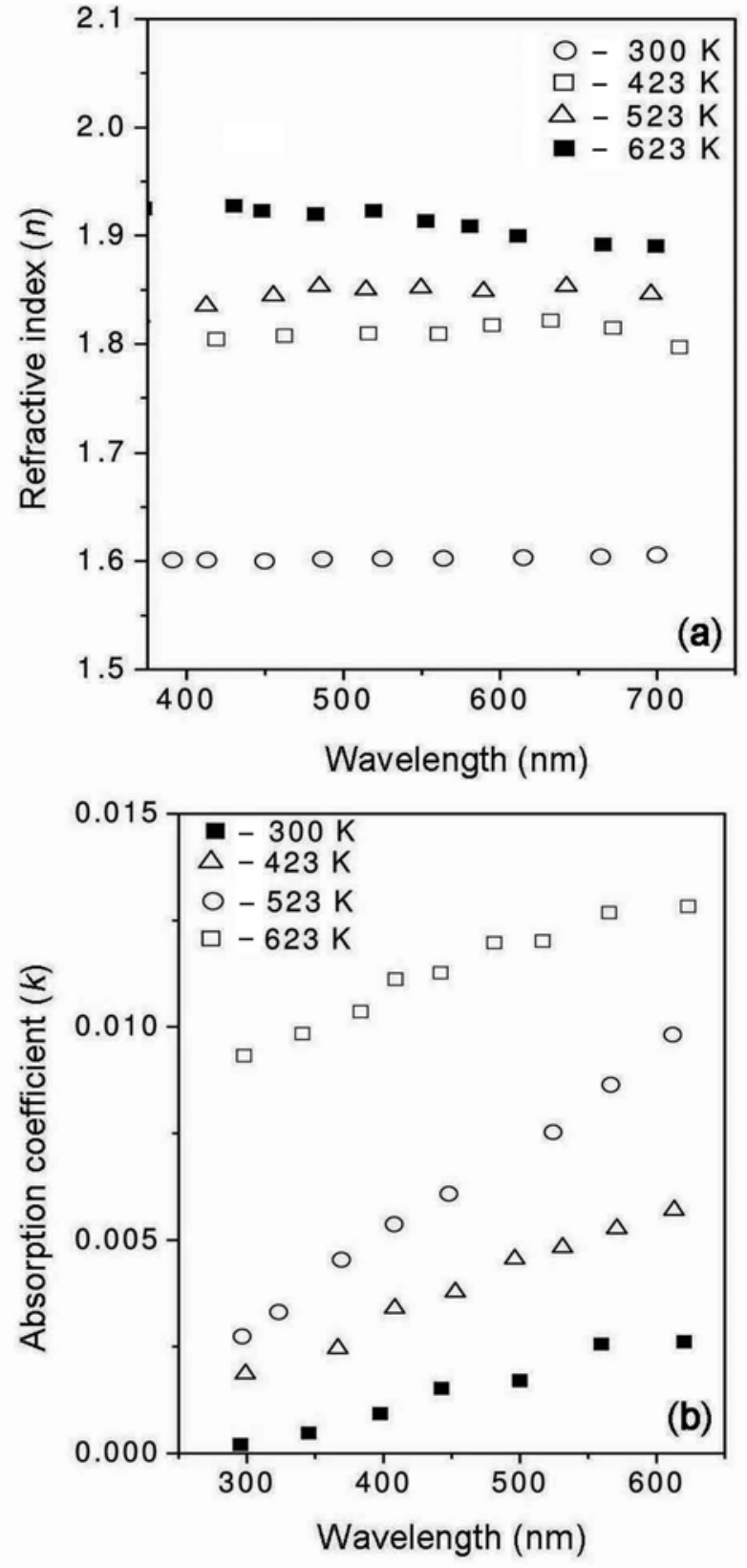

Figure 6. Variation of (a) refractive index $(n)$ and (b) extinction coefficient $(k)$ with energy for four representative Si-doped GaN films.

surface $^{21}$ considering a Gaussian distribution of the crystallite size $(D)$

$$
P(D)=\left(D-D_{\min }\right)\left(D_{\max }-D\right) \exp \left(-D^{2} / \delta^{2}\right),
$$

where $D_{\max }$ and $D_{\min }$ are the maximum and minimum diameters of the grains and $\delta$ the half-width of the grain distribution; $D_{\max }=\bar{D}+\delta$ and $D_{\min }=\bar{D}-\delta, \bar{D}$ being the average radius. The distribution of grains thus obtained for films deposited at two different temperatures (corresponding SEM micrographs are shown in figure 1) is also shown in figure 1. Variation of the average grain 

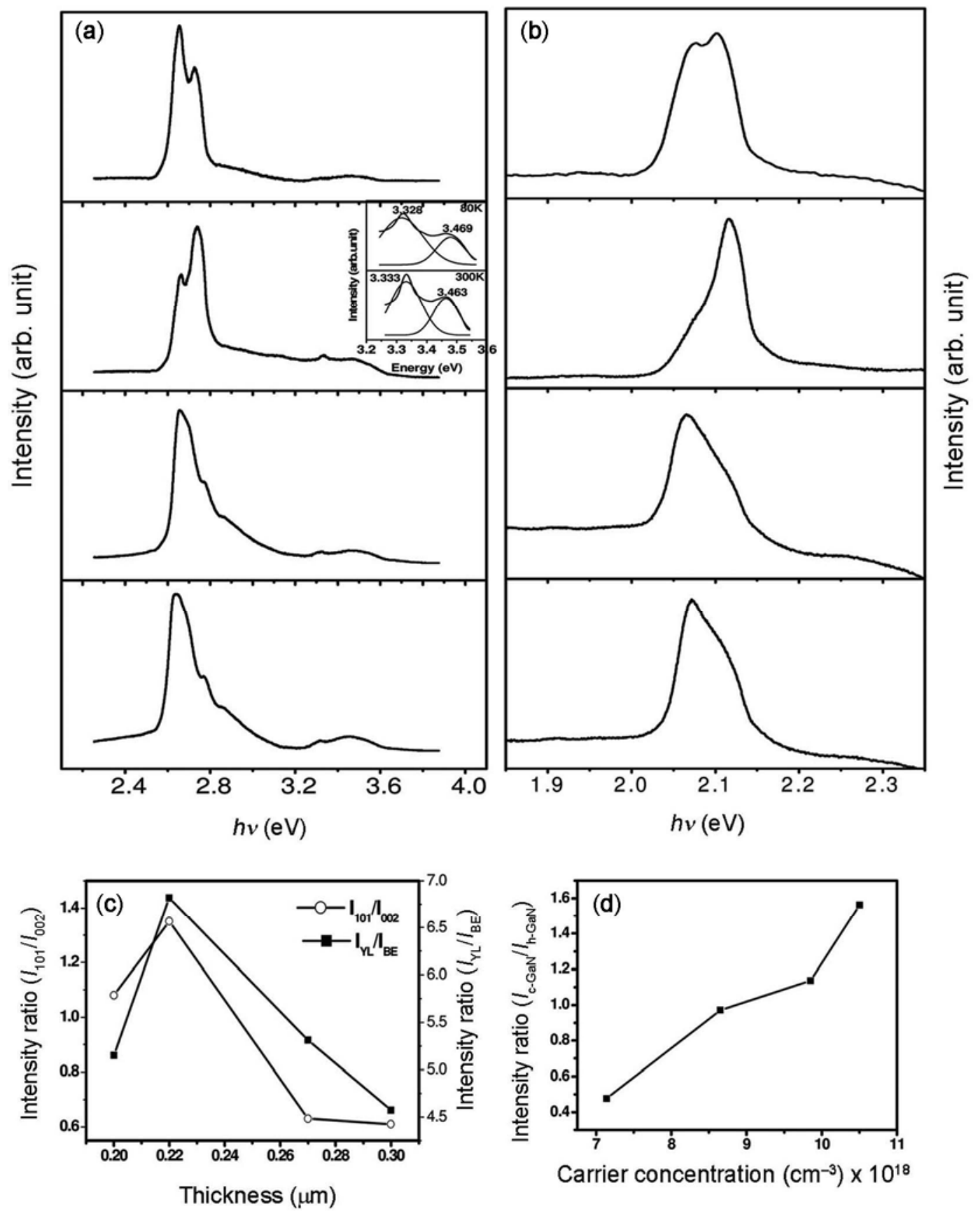

Figure 7. PL spectra of two representative Si-doped GaN films deposited (a) in the range of 320$550 \mathrm{~nm}$ and (b) in the range of 550-675 nm. (c) Intensity ratio of h-GaN to c-GaN and YL to BE emission with respect to grain size and (d) Intensity of $I_{\mathrm{h}-\mathrm{GaN}} / I_{\mathrm{c}-\mathrm{GaN}}$ with respect to carrier concentration.

diameter of our GaN films (thickness $\sim 1 \mu \mathrm{m}$ ) deposited at different substrate temperatures has been shown in figure 5. This agreed well with that obtained from SEM studies.

\subsection{Photoluminescence (PL) studies}

PL measurements were recorded at 80 and $300 \mathrm{~K}$ by using a $300 \mathrm{~W}$ xenon arc lamp as the emission source. A
Hamamatsu photomultiplier along with a $1 / 4 \mathrm{~m}$ monochromator was used as the detector. The spectra were recorded with excitation at $300 \mathrm{~nm}$ radiation for detecting PL peaks in the range $320-550 \mathrm{~nm}$ while for detecting peaks in the range $550-675 \mathrm{~nm}$, an excitation energy of $435 \mathrm{~nm}$ was used. PL spectra were recorded as above at $80 \mathrm{~K}$ in the range of $320-550$ and $550-675 \mathrm{~nm}$ as shown in figures $7 \mathrm{a}$ and $\mathrm{b}$, respectively. The spectra were recorded at increasing substrate temperature 
(300-623) from bottom to top. The luminescence at $\sim 2.7 \mathrm{eV}$ indicated blue emission $(\mathrm{BE})^{9}$ and could be identified as arising from the transitions between deep donor and induced shallow acceptor by $\mathrm{Si}$ impurity without $d$ electron. The origin of the deep donor might be due to nitrogen vacancy ${ }^{10}$ or $\mathrm{Ga}$ interstitial-related defects. There are two other peaks located at $\sim 2.8$ and $\sim 2.85 \mathrm{eV}$ (in the low-temperature region), which may result from radiative recombination related to the Urbach tail region and it was considered that it has a large potential fluctuation due to the grain to grain band discontinuity or the piezoelectric field, especially because of the coexistence of the grains with different orientations. ${ }^{10,22}$ The transitions located between $\sim 2.1$ and $2.065 \mathrm{eV}$ may be ascribed to the transitions between shallow donor and deep acceptor levels. This is the typical signature of yellow luminescence (YL) in GaN having multicomponent nature, which is very sensitive to the exact nature of distribution of the defects. ${ }^{23}$ The deep acceptor levels might arise either due to $\mathrm{Ga}$ vacancy $\left(\mathrm{V}_{\mathrm{Ga}}\right)$ or $\mathrm{Ga}$ vacancy with oxygen on a nitrogen site complex $\left(\mathrm{V}_{\mathrm{Ga}}-\mathrm{O}_{\mathrm{N}}\right)$ and are the key defects responsible for $\mathrm{YL}$ in $\mathrm{GaN}^{6}{ }^{6}$ The film surface is $\mathrm{N}$ rich in the presence of $\mathrm{N}_{2}$ plasma and $\mathrm{Ga}$ rich in the presence of $\mathrm{Ar}$ plasma. Under N-rich condition the $\mathrm{O}_{\mathrm{N}}$ ( $\mathrm{O}$ on $\mathrm{N}$ sites) is less likely to form, which suppresses the formation of $\mathrm{O}_{\mathrm{N}}-\mathrm{V}_{\mathrm{Ga}}$ complex. That is why it is preferred to continue the whole experiment using Ar plasma. Small PL peaks were located at high energy sides, $\sim 3.46^{4}$ and $\sim 3.3 \mathrm{eV},{ }^{24}$ and could be identified as due to excitons bound to a neutral donor for $\mathrm{h}-\mathrm{GaN}$ and c-GaN, respectively. Inset of figure $7 \mathrm{a}$ shows the room-temperature $(300 \mathrm{~K})$ and low-temperature $(80 \mathrm{~K}) \mathrm{PL}$ of a representative film in the $\mathrm{BE}$ emission region, which indicates the change in position, height and FWHM due to temperature difference. This is in conformity with the XRD and optical studies, which have indicated that the films contained both the h-GaN and c-GaN phases.

In order to determine the influence of structural defects on the YL emissions in the poly-GaN films both the intensity ratios of (101) to (002) diffraction peaks and YL and $\mathrm{BE}$ emissions are plotted in figure 7c, respectively. In general the intensity ratio of this diffraction peak is used to evaluate the crystalline quality of GaN films, ${ }^{25}$ and that of YL to BE indicates the optical properties, ${ }^{26}$ respectively. Considering the same trends between both intensity ratios of (101) to (002) peak and YL to BE emission, it was considered that the (101) atomic facet was associated with the YL in poly-GaN films on silica substrates. It was typically known that the gallium vacancies and impurity complexes, which were trapped at the structural defects such as dislocations and grain boundaries, were responsible for the YL emission in GaN materials. ${ }^{27,28}$ Recently, it has been reported that the YL emission has been attributed to the atomic facets of (1010) and (1011) in GaN materials. $^{25,29}$

\subsection{Carrier concentration determination from $C-V$ analysis}

The carrier concentration $(N)$ obtained from $C-V$ analysis using $\mathrm{Ag} / \mathrm{GaN} / \mathrm{SnO}_{2}$ Schottky diode structure ${ }^{30}$ at a frequency of $100 \mathrm{kHz}$ varied from $9.54 \times 10^{18}$ to $2.48 \times$ $10^{19} \mathrm{~cm}^{-3}$ with increasing substrate temperature, whereas in undoped sample it was noticed that it changed from $\sim 10^{16}$ to $10^{17} \mathrm{~cm}^{-3}$. To characterize the effect of Si doping on the $\mathrm{h}-\mathrm{GaN}$ to $\mathrm{c}-\mathrm{GaN}$ phase transformation, the intensity ratio $I_{\mathrm{h}-\mathrm{GaN}} / I_{\mathrm{c}-\mathrm{GaN}}$ with respect to carrier concentration is considered in figure $7 \mathrm{~d}$. As the carrier concentration is increased with the change in temperature, the fraction of $\mathrm{c}-\mathrm{GaN}$ increased. The latter finding may be co-related with the bandgap transformation from h-GaN to c-GaN as shown in figure 5. The mechanism of phase transformation in GaN is generally thought to be due to stacking particle always in dislocations associated with it. The particle then grows by $\mathrm{Si}$ diffusion to its surface. The large volume change also requires that the $\mathrm{Ga} / \mathrm{N}$ ratio of atoms should be displaced from the vicinity/matrix interface. This may be accomplished by the generation of interstitial $\mathrm{Ga} / \mathrm{N}$ at the particle/matrix interface. This excess interstitials can form stacking faults. ${ }^{31,32}$ These stacking faults in turn form the channels of the phase transformation.

\section{Conclusion}

Polycrystalline Si-doped GaN films were deposited with different grain sizes by varying the substrate temperature during r.f. sputtering of the $\mathrm{GaN}$ target. Grain size increased from $\sim 0.2$ to $\sim 0.35 \mu \mathrm{m}$ as the substrate temperature during deposition was increased from 300 to $623 \mathrm{~K}$, which is in good agreement with optical measurements and XRD studies. The films showed predominant hexagonal structure when deposited at $T<423 \mathrm{~K}$, while those deposited at $T>523 \mathrm{~K}$ were found to be rich in cubic phase. The XRD traces contained the signature of both the hexagonal and cubic phases of GaN. The PL peak at $\sim 2.7 \mathrm{eV}$ could be identified as arising due to the transitions between deep donor and induced shallow acceptor due to Si impurity without $d$ electron. The (101) atomic facet was associated with the YL in poly-GaN films on silica substrates located between $\sim 2.1$ and $2.065 \mathrm{eV}$. Small PL peaks located at high energy sides, 3.46 and $3.3 \mathrm{eV}$, could be identified as due to excitons bound to a neutral donor for h-GaN and c-GaN, respectively. Particle grows by $\mathrm{Si}$ diffusion through the film surface, and the variation of substrate temperatures are the reason of different proportions in cubic and hexagonal phases of the films. The carrier concentration varied from $9.54 \times 10^{18}$ to $2.48 \times 10^{19} \mathrm{~cm}^{-3}$ with increase in substrate temperature, whereas in undoped sample we have noticed that it changed from $\sim 10^{16}$ to $10^{17} \mathrm{~cm}^{-3}$. 


\section{References}

1. Jenkins D W and Dow J D 1989 Phys. Rev. B 393317

2. Neugebaur J and Van der Walle C G 1994 Phys. Rev. B 50 8067

3. Li Z Q, Chen H, Liu H F, Wan L, Huang Q and Zhou J M 2001 J. Cryst. Growth 227-228 420

4. Hasegawa S, Nishida S, Yamashita T and Asahi H 2005 Thin Solid Films 487260

5. Tampo H, Asahi H , Imanishi Y, Hiroki M, Ohnishi K, Yamada K, Asami K and Gonda S 2001 J. Cryst. Growth 227-228 442

6. Yu H B, Chen H, Li D, Han Y J, Zheng X H, Huang Q and Zhou J M 2004 J. Cryst. Growth 26394

7. Park S E, Kim D J and Byungsung O 2003 J. Cryst. Growth 25287

8. Park S E, Kim D J, Woo S W, Lim S M and Byungsung O 2002 J. Cryst. Growth 242383

9. Maa H L, Yang Y G, Maa J and Liuc X M 2004 Diam. Relat. Mater. 131892

10. Yang Y, Yu K and Zhang Y 2004 Physica B 3521

11. Maruyama T and Miyake H 2006 J. Vac. Sci. Technol. A 24 1096

12. Chowdhury M P, Roy R K, Chakraborty B R and Pal A K 2005 Thin Solid Films 49129

13. Chen R, Zhou W and Kwok H S 2012 Appl. Phys. Lett. 100 253501

14. Zou C W, Wang H J, Yin M L, Li M, Liu C S, Guo L P, Fu D J and Kang T W 2009 J. Cryst. Growth 311223

15. Niehus M et al 2004 J. Non-Cryst Solids 338-340 460

16. Wang $\mathrm{F}$ Y, Wang $\mathrm{R} \mathrm{Z}$, Zhao W, Song X M, Wang B and Yan H 2009 Sci. China Series F: Inform. Sci. 52 1947
17. Hong J-II, Chang Y, Ding Y, Wang Z L and Snyder R L 2011 Thin Solids Films 5193608

18. Lopez N P, Tao J H, McKittrick J, Talbot J B, Raukas M, Laski J, Mishra K C and Hirata G 2008 Phys. State Sol. (C): Curr. Topics Solid State Phys. 51756

19. Bhattacharyya D, Chaudhuri S and Pal A K 1992 Vacuum 43313

20. Manifacier J C, Muricia M D, Fillard J P and Vicario E 1977 Thin Solid Films 41127

21. Bhattacharyya D, Chaudhuri S and Pal A K 1993 Vacuum 44797

22. Hiroki M, Asahi H, Tampo H, Asami K and Gonda S 2000 J. Cryst. Growth 209387

23. Kucheyev S O, Toth M, Phillips M R, Williams J S, Jagadish C and Li G 2002 Appl. Phys. Lett. 915867

24. Rieger W, Dimitrov R, Brunner D, Rohrer E, Ambacher O and Stutzmann M 1996 Phys. Rev. B 5417596

25. Yang S H, Ahn S H, Jeong M S, Nahm K S, Suh E K and Lim K Y 2000 Solid State Electron. 441655

26. Li X and Coleman J J 1997 Appl. Phys. Lett. 7027

27. Hansen P J, Strausser Y E, Erickson A N, Tarsa E J, Kozodoy P, Brazel E G, Ibbetson J P, Mishra U, Narayanamurti V, DenBaars S P and Speck J S 1998 Appl. Phys. Lett. 722247

28. Timmers H, Chen A, Patrick P T, Weijers T D M, Goldys E M, Tansley T L, Elliman R G and Freitas J A 2002 J. Appl. Phys. 923397

29. Li X, Bohn P W and Coleman J J 1999 Appl. Phys. Lett. 75 4049

30. Deb B, Ganguly A, Chaudhuri S, Chakraborti B R and Pal A K 2002 Mater. Chem. Phys. 74282

31. Patel J R, Jackson K A and Reiss H J 1977 J. Appl. Phys. 485279

32. Xu D, Yang H, Li J B, Li S F, Wang Y T, Zhao D G and Wu R H 1999 J. Cryst. Growth 206150 